\title{
A MODIFIED KAPANDJI PROCEDURE FOR SMITH'S FRACTURE IN CHILDREN
}

\author{
JEAN-MARC GUICHET, CEA-CEA MOLLER， GILLES DAUTEL， PIERRE LASCOMBES
}

From the Children's Hospital, Vandoeuvre-Lès-Nancy, France

\begin{abstract}
Anteriorly displaced fractures of the wrist can be treated by the Kapandji technique of percutaneous intrafocal pinning with pins inserted through an anterior approach to give good reduction and stabilisation of the fracture. We have modified this technique by placing the pins through a posterior approach which decreases the risks of neurovascular damage.
\end{abstract}

We have used this method to treat six children with distal radial fractures showing anterior displacement or instability. Good anterior stabilisation was achieved. The pins were removed at an average of eight weeks and the patients were then able to return to full activity.

This simple technique can be used for unstable fractures after the failure of conservative treatment or in bilateral fractures in adolescents.

J Bone Joint Surg [Br] 1997;79-B:734-7.

Received 22 January 1997; Accepted after revision 8 April 1997

A Smith's fracture may be treated operatively by a buttress plate, ${ }^{1}$ Kirschner (K-) wires or external fixation. ${ }^{2}$ Hoël and Kapandji ${ }^{3}$ developed a percutaneous technique using two anterior skin incisions, $5 \mathrm{~mm}$ medial to the radial artery and lateral to the ulnar artery, to pass Kirschner wires into the fracture site before reducing the fracture. The wires were then advanced into the posterior cortex at an angle of $45^{\circ}$. This blind approach may, however, put the adjacent vessels, tendons and nerves at risk.

We have used a reversed Kapandji technique with the

J.-M. Guichet, MD, PhD, Fellow in Orthopaedic Surgery

C.-C. Moller, MB BS, Resident

G. Dautel, MD, Professor

P. Lascombes, MD, Professor

Department of Orthopaedics, Children's Hospital, 54511 Vandoeuvre-LèsNancy, France.

Correspondence should be sent to Dr J.-M. Guichet at 2 Square Alexis Carrel, 54600 Villers-Lès-Nancy, France.

(c)1997 British Editorial Society of Bone and Joint Surgery 0301-620X/97/57620\$2.00 pins introduced through a posterior approach and locked at the anterior cortex at the fracture site after reduction. We report our results in six patients.

\section{PATIENTS AND METHODS}

Between June 1995 and April 1996 we treated six patients aged from 9 to 15 years (Table I). Percutaneous wiring was chosen either because of bilateral fracture in an adolescent, instability or failure of conservative treatment.

Operative technique. Under fluoroscopic control, the radius is approached posteriorly and proximally at an angle of $60^{\circ}$ to the anterior cortex at the fracture site (Fig. 1). A Kwire, $2 \mathrm{~mm}$ in diameter, is introduced percutaneously medial to the extensor pollicis longus, passed between the tendons and through the posterior cortex. The wire is then replaced with a partially-threaded pin trimmed to keep $5 \mathrm{~mm}$ of thread which is introduced up to the anterior margin of the fracture. Non-threaded pins are not recommended because they may migrate. Reduction is achieved by traction and by extension of the distal radius while the wire is advanced $3 \mathrm{~mm}$ through the fracture. After this the traction is released. Additional lateral or posterior wires can be placed if necessary. The stability achieved is demonstrated by maximal flexion and extension of the wrist under
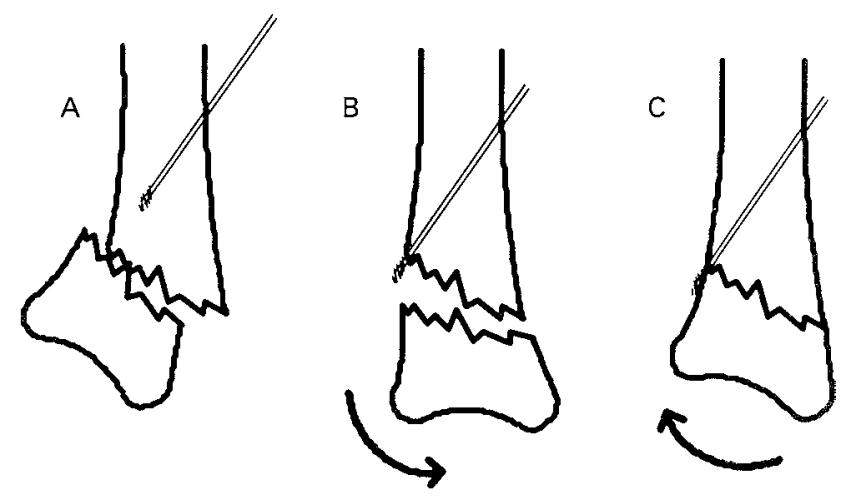

Fig. 1

Method of insertion of the K-wires in Smith's fractures showing introduction of the K-wire (a), over-reduction of the fracture and placement of the $\mathrm{K}$-wire (b), and release of traction with the distal fragment now buttressed anteriorly (c). 
Table I. Details of the six patients

\begin{tabular}{|c|c|c|c|c|c|c|c|}
\hline Case & Gender & Age (yr) & Injury & Primary treatment & $\begin{array}{l}\text { Reason for } \\
\text { operation }\end{array}$ & Follow-up & Result \\
\hline 1 & M & 14 & $\begin{array}{l}\text { Bilateral wrist fractures: } \\
\text { right, Colles type; left, } \\
\text { anterior displacement }\end{array}$ & Kapandji both sides & Bilateral injury & $1 \mathrm{yr}$ & Excellent \\
\hline 2 & M & 15 & $\begin{array}{l}\text { Salter-Harris II fracture } \\
\text { of distal radius with } \\
\text { anterior displacement } \\
\text { Ulnar fracture }\end{array}$ & $\begin{array}{l}\text { MAN* } \\
\text { Above-elbow cast }\end{array}$ & Ischaemia of hand & 10 days & $\begin{array}{l}\text { No loss of reduction of } \\
\text { the fracture }\end{array}$ \\
\hline 3 & M & 14 & $\begin{array}{l}\text { Fracture distal radius } \\
\text { with posterior displacement } \\
\text { Ulnar fracture }\end{array}$ & MAN & $\begin{array}{l}\text { Fracture unstable } \\
\text { Associated fixation } \\
\text { of the ulna }\end{array}$ & $1 \mathrm{yr}$ & $\begin{array}{l}\text { Power in wrist normal } \\
\text { Slight loss of movement } \\
\text { due to } 15^{\circ} \text { posterior tilt } \\
\text { Pain in ulna on } \\
\text { prolonged supination }\end{array}$ \\
\hline 4 & $\mathrm{~F}$ & 10 & $\begin{array}{l}\text { Fracture of distal radius } \\
\text { with anterior tilt } \\
\text { Greenstick fracture of ulna }\end{array}$ & $\begin{array}{l}\text { MAN } \\
\text { Above-elbow cast } \\
\text { for six weeks }\end{array}$ & Loss of position & $5 \mathrm{mth}$ & $\begin{array}{l}\text { Good result } \\
\text { No complications }\end{array}$ \\
\hline 5 & M & 9 & $\begin{array}{l}\text { Fracture of distal radius } \\
\text { with posterior angulation } \\
\text { and overriding } \\
\text { Ulnar fracture }\end{array}$ & $\begin{array}{l}\text { MAN with } \\
\text { immobilisation in cast } \\
\text { Repeated at } 3 \text { days } \\
\text { for loss of position }\end{array}$ & $\begin{array}{l}\text { Further loss of } \\
\text { position at two weeks }\end{array}$ & $9 \mathrm{mth}$ & $\begin{array}{l}\text { Full range of movement } \\
\text { Pain on forced supination }\end{array}$ \\
\hline 6 & M & 9 & $\begin{array}{l}\text { Compound fracture of } \\
\text { distal metaphysis of } \\
\text { radius with anterior } \\
\text { angulation } \\
\text { Ulnar fracture }\end{array}$ & $\begin{array}{l}\text { Examination under } \\
\text { anaesthesia }\end{array}$ & $\begin{array}{l}\text { Fracture unstable } \\
\text { Carpal tunnel } \\
\text { release }\end{array}$ & $5 \mathrm{mth}$ & $\begin{array}{l}\text { Slight loss of movement } \\
\text { Dorsal paraesthesiae on } \\
\text { percussion of the } \\
\text { proximal part of the } \\
\text { 5th metacarpal }\end{array}$ \\
\hline
\end{tabular}

* manipulation under anaesthesia

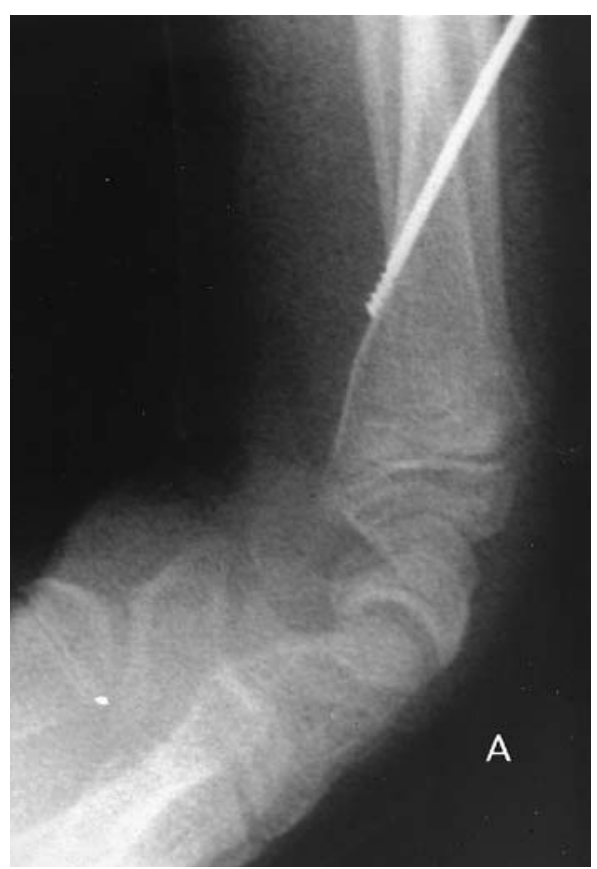

Fig. 2a

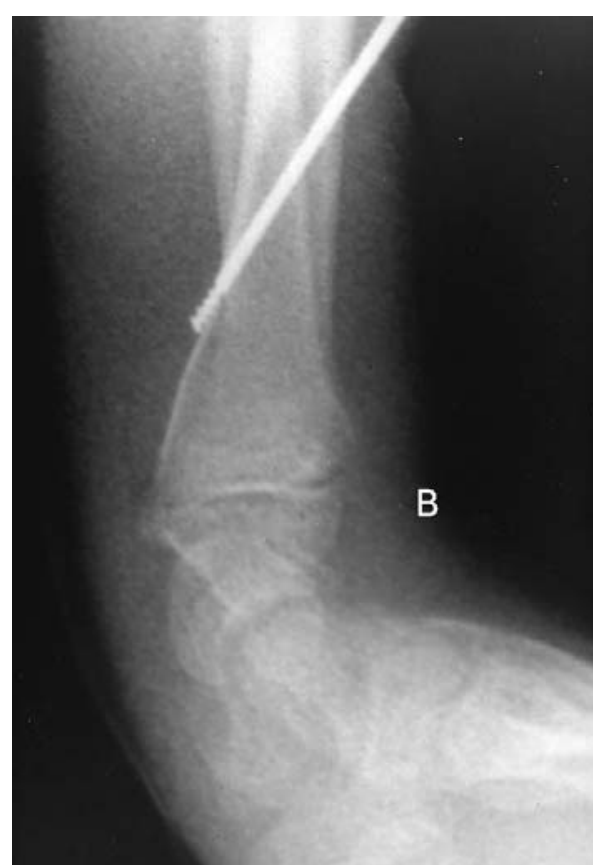

Fig. 2b

Case 1. Lateral peroperative radiographs of the wrist showing stability in full flexion (a) and full extension (b) after the insertion of the anteroposterior pin.

image-intensifier control (Fig. 2).

After operation the wrist was immobilised in an anterior splint or cast for a mean of six weeks (2 to 9). The wires were removed after a mean of eight weeks.

The mean follow-up in our six patients was eight months. Flexion, extension, pronation, supination and radial and ulnar deviation were measured in degrees and compared with those of the opposite side. Lateral shift, shortening and anterior tilt of the distal radius were assessed radiologically. ${ }^{4}$ 


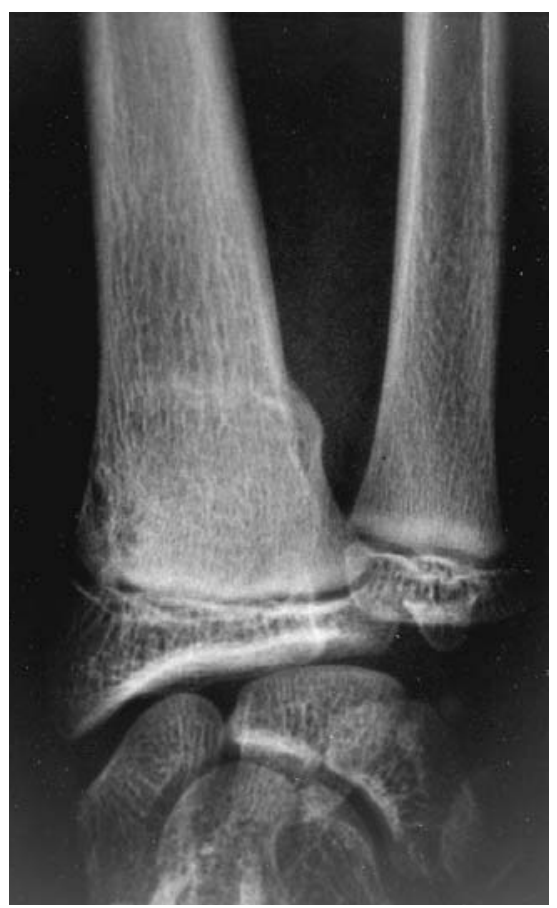

Fig. 3a

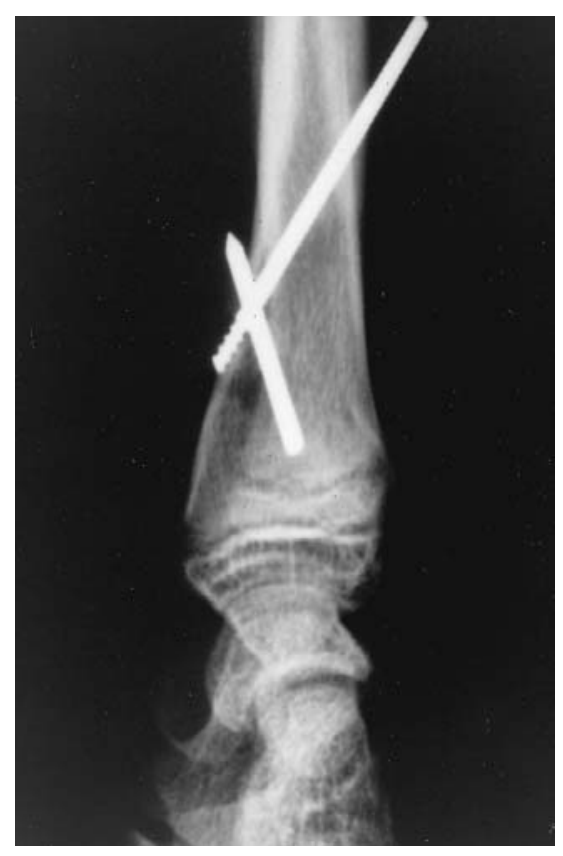

Fig. 3d

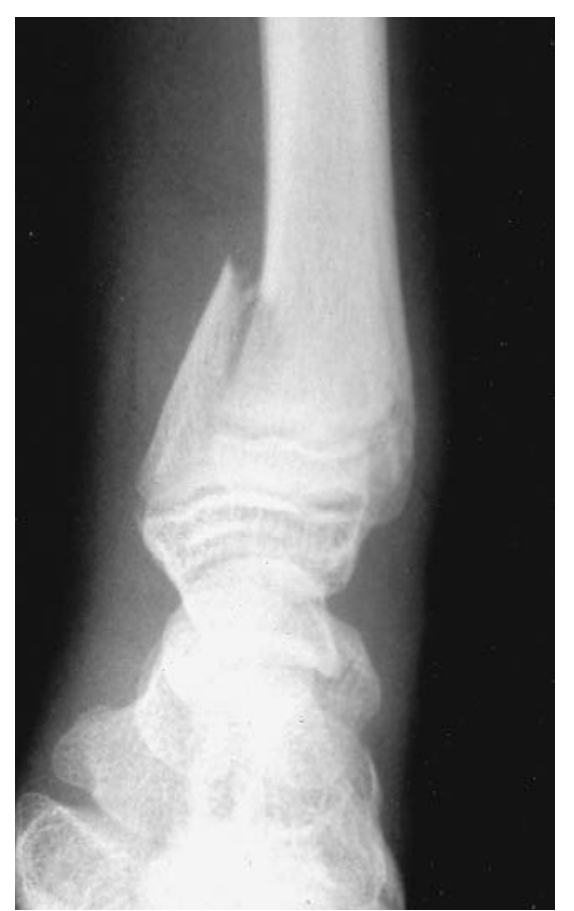

Fig. 3b

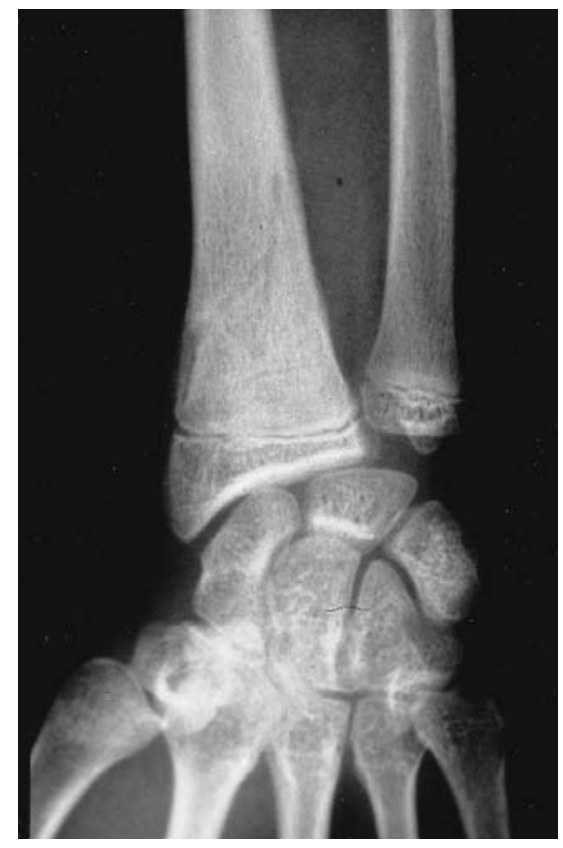

Fig. 3e

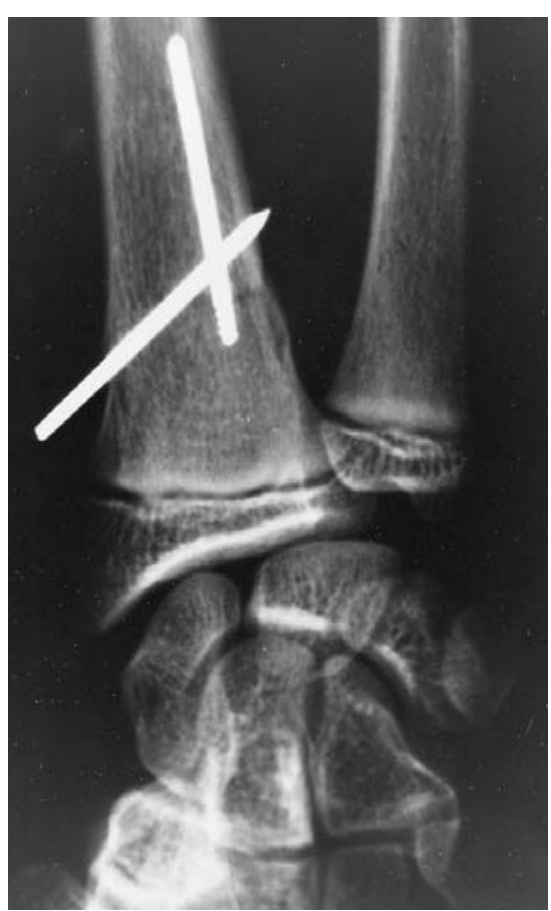

Fig. 3c

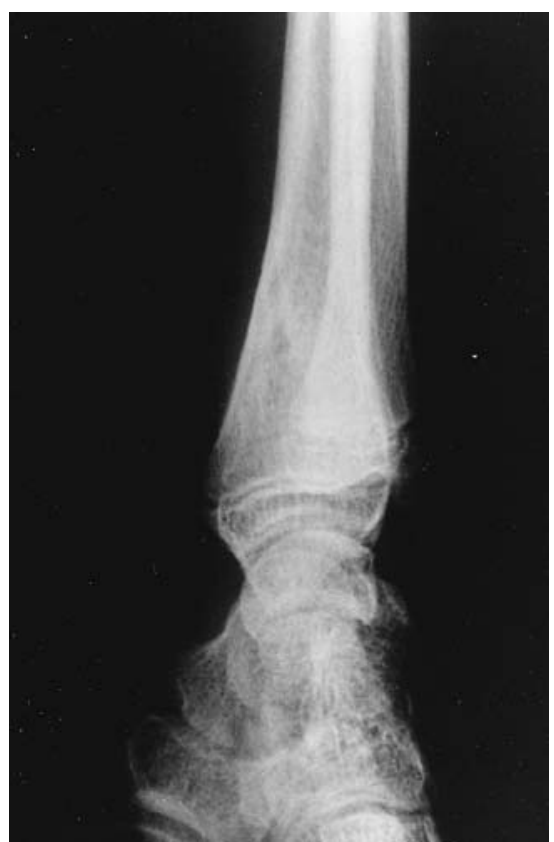

Fig. $3 f$

Case 1. Anteroposterior (a) and lateral (b) radiographs of the left wrist showing the fracture. Anteroposterior (c) and lateral (d) radiographs after stabilisation. Anteroposterior (e) and lateral (f) radiographs after removal of the pins.

\section{RESULTS}

All the patients had satisfactory improvement in the position of the fracture as judged radiologically (Table I; Fig 3). One was lost to follow-up after ten days, at which stage the anatomical reduction was perfect, with no secondary dis- placement. At the final follow-up at a mean of eight months, three patients were completely free from symptoms with full function, one (case 3) had pain on the medial side of the wrist after prolonged supination while playing a guitar, one (case 5) had pain on the ulnar side on forced or rapid supination and another (case 6) experienced dorsal 


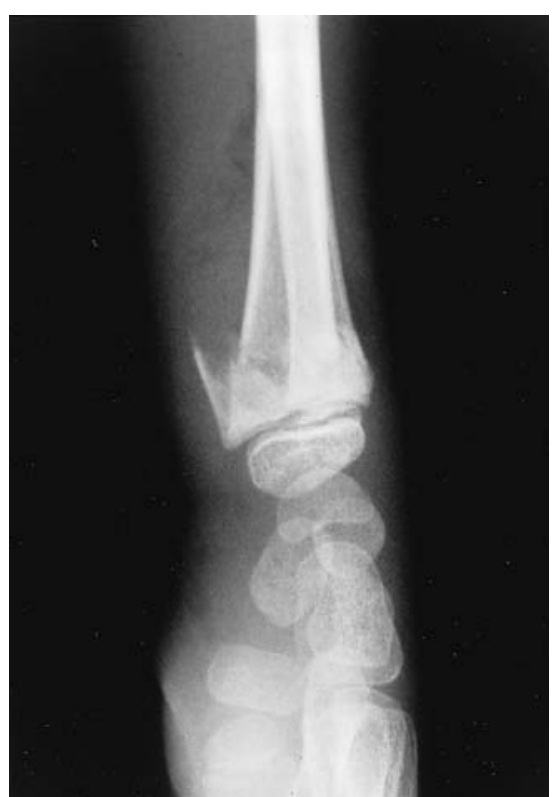

Fig. 4a

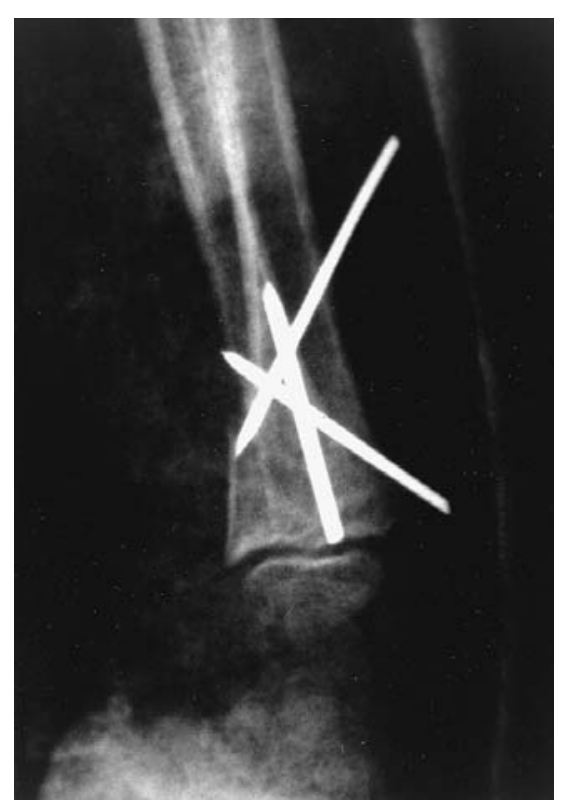

Fig. 4b

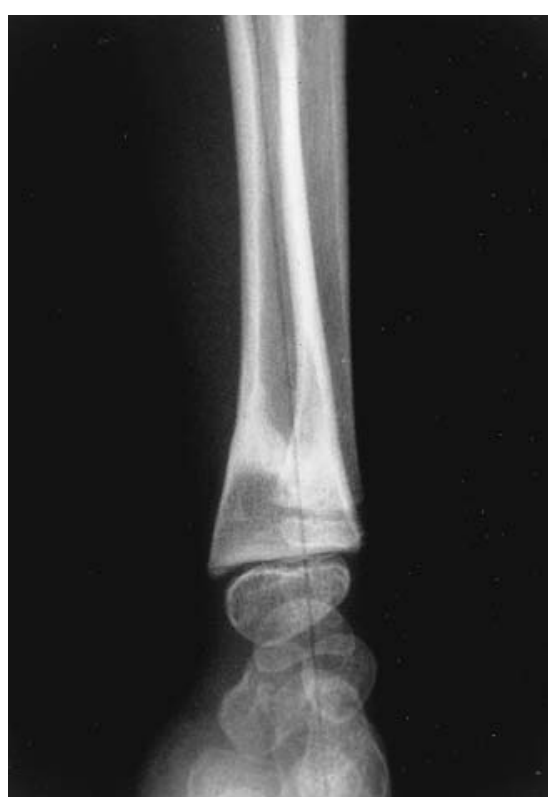

Fig. 4c

Case 6. Lateral radiograph of the wrist after injury (a), after fixation (b), and five months after operation (c).

paraesthesiae and showed a minimal decrease in flexion and ulnar deviation (Fig. 4).

\section{DISCUSSION}

An anterior buttress plate is recommended for the treatment of fractures of the wrist with anterior displacement. In adults, $28 \%$ of these fractures show malunion with an overall complication rate of $40 \%{ }^{4}$ In children, the use of a buttress plate may give problems because of the open growth plate, the need for a large incision, and for general anaesthesia when the plate is removed.

The Kapandji technique is widely used in Europe for treating fractures of the wrist with posterior displacement. Hoël and Kapandji ${ }^{3}$ used a modification of the classic technique with a volar approach for fractures with anterior displacement. This approach may be risky in inexperienced hands because of the important structures which lie nearby.

We have changed the direction of insertion of the wires to provide a greater margin of safety and have used wires with a distal thread to avoid secondary slipping. The pin should be thin enough to allow accurate reduction of the fracture and sit snugly next to the anterior cortex to prevent secondary displacement of the epiphysis. If considerable callus has already formed the pins are best inserted directly into it. The method is best reserved for metaphyseal rather than more proximal fractures. Our results were good, given that the technique was applied to difficult fractures.

No benefits in any form have been received or will be received from a commercial party related directly or indirectly to the subject of this article.

\section{REFERENCES}

1. Seriat-Gautier B, Jouve JL. Avulsion fractures of the distal part of the radius with anterior displacement in children. Chir Pédiatr 1988; 29:265-8.

2. Louis DS. Barton's and Smith's fractures. Hand Clin 1988;4: 399-402.

3. Hoël G, Kapandji AI. Osteosynthesis using intrafocal pins of anteriorly dislocated fractures of the inferior radial epiphysis. Ann Chir Main Memb Super 1995;14:142-57.

4. Keating JF, Court-Brown CM, McQueen MM. Internal fixation of volar-displaced distal radial fractures. J Bone Joint Surg [Br] 1994; 76-B:401-5. 